\title{
Association of diabetes mellitus with clinical outcomes in patients with different coronary artery stenosis
}

Hui-Wen Zhang, Jing-Lu Jin, Ye-Xuan Cao, Yuan-Lin Guo, Na-Qiong Wu, Cheng-Gang Zhu, Rui-Xia Xu, Qian Dong and Jian-Jun Li* (1)

\begin{abstract}
Background: It has been demonstrated that patients with type 2 diabetes mellitus (DM) is associated with increased cardiovascular risk. However, little is known regarding the long-term prognosis in diabetic patients who experience mild-to-intermediate coronary artery stenosis (CAS). This study was to assess the clinical outcomes of diabetic patients with different severity of CAS.

Methods: We consecutively enrolled 10,940 patients hospitalized due to angina-like chest pain and followed up for major adverse cardiovascular events (MACEs) covering cardiac death, myocardial infarction, ischemic stroke, unplanned coronary revascularization and angina-related hospitalization. According to coronary angiography, patients were divided into non-obstructive CAS (NOCAS, < 50\% stenosis), intermediate CAS (ICAS, 50-69\% stenosis), and severe CAS (SCAS, 70-100\% stenosis) subgroups, and were further categorized into six groups as NOCAS with DM and non-DM, ICAS with DM and non-DM, and SCAS with DM and non-DM.

Results: During a median follow-up of 40 months, 1,017 (11.1\%) MACEs occurred. In patients with ICAS or SCAS, the incidence of events was higher when patients coexisted with $\mathrm{DM}(\mathrm{p}<0.05$, respectively). In subgroup analyses, patients with ICAS and DM, SCAS and non-DM, SCAS and DM had increased risk of events [adjusted hazard ratio (HR): $1.709,95 \%$ confidence interval (Cl) 1.106-2.641, $p=0.016$; HR: 1.911, 95\% Cl 1.460-2.501, $p<0.001 ; \mathrm{HR}: 2.053,95 \% \mathrm{Cl}$ 1.514-2.782, $p<0.001]$ compared to ones with NOCAS and non-DM. Besides, the Kaplan-Meier curves indicated the highest risk of MACEs in patients with SCAS and DM than others $(p<0.001)$.
\end{abstract}

Conclusions: Diabetic patients with ICAS had the worse outcome, which was comparable to patients with SCAS alone.

Keywords: Diabetes mellitus, Coronary artery stenosis, Cardiovascular events

*Correspondence: lijianjun938@126.com

State Key Laboratory of Cardiovascular Disease, National Clinical Research Center for Cardiovascular Diseases, Fu Wai Hospital, National Center for Cardiovascular Diseases, Chinese Academy of Medical Sciences and Peking Union Medical College, No 167 BeiLiShi Road, XiCheng District, Beijing 100037, China

\section{Introduction}

Type 2 diabetes mellitus (DM) is a major risk factor of cardiovascular disease [1-3]. The cardiovascular mortality is increased by more than two-fold in diabetic patients compared to those without [2-5]. Previous studies have revealed that patients with $\mathrm{DM}$ are also subjected to worse cardiovascular outcomes [2-8], especially in those coexisted with coronary artery diseases (CAD) [7, 8]. Notably, in diabetic patients with CAD, the pathological original author(s) and the source, provide a link to the Creative Commons licence, and indicate if changes were made. The images or other third party material in this article are included in the article's Creative Commons licence, unless indicated otherwise in a credit line to the material. If material is not included in the article's Creative Commons licence and your intended use is not permitted by statutory regulation or exceeds the permitted use, you will need to obtain permission directly from the copyright holder. To view a copy of this licence, visit http://creativecommons.org/licenses/by/4.0/. The Creative Commons Public Domain Dedication waiver (http://creativeco mmons.org/publicdomain/zero/1.0/) applies to the data made available in this article, unless otherwise stated in a credit line to the data. 
feature of coronary lesions is more complicated, which is characterized by calcified, diffuse, multivessel disease, and greater atherosclerotic plaque burden $[9,10]$. Therefore, these patients often require assessment of coronary lesions and revascularization in addition to optimal medical therapy to control angina [11].

Clinically, a quite large proportion of patients (30\% to $70 \%$ ) receiving coronary angiography (CAG) due to angina-like chest pain do not present severe obstructive stenosis in coronary arteries [12-14]. Importantly, most of these patients presented a mild or moderate coronary stenosis but continue to experience recurrent angina. Additionally, they might be also subjected to high healthcare costs due to repeating hospitalization and coronary artery angiograms, and even high risk of adverse cardiovascular event. [14-16]. More recently, an expert consensus document published in European Heart Journal stressed on this issue, indicating that patients with ischemia with non-obstructive coronary arteries were also independently associated with poor clinical outcomes and required future ongoing research for comprehensive management in such patients [17].

To our knowledge, less data is currently available regarding the joint impact of DM on clinical outcomes in a large cohort who suffer from mild-to-intermediate coronary artery stenosis (CAS). Therefore, the aim of the present study was to explore the prognostic association of type 2 diabetic patients with different CAS assessed by selective CAG in a large Chinese cohort.

\section{Material and methods Study population}

From April 2011 to March 2018, a total of 10,940 consecutive patients were hospitalized due to angina-like chest pain in FuWai Hospital (National Center for Cardiovascular Diseases, Beijing, China). The study flowchart of this observational prospective study was shown in Fig. 1. Briefly, patients who met the exclusion criteria: under 18 years-old, severe liver and renal dysfunction, severe infectious or systematic inflammatory diseases, significant hematologic disorders, malignant cancer, decline to participate; patients without CAG; or patients lost follow-up were excluded. The indications for CAG including patients with angina-like chest pain, and/or with positive treadmill exercise test, and/or with significant coronary stenosis assessed by computed tomography angiography (CTA) [18]. Finally, a total of 9091 eligible patients received CAG were enrolled, including 6918 stable angina, 1380 unstable angina, and 793 old myocardial infarction (MI). Among them, 4493 patients received coronary revascularization in hospital, including 4306 patients underwent percutaneous coronary intervention
(PCI), and 187 patients did coronary artery bypass graft (CABG).

This study complied with the Declaration of Helsinki and was approved by the hospital ethical review board (Approval No.: 2013-442. FuWai Hospital and National Center for Cardiovascular Diseases, Beijing, China). The informed written consent was obtained from all patients.

\section{Definitions}

The CAG was invasively obtained via heart catheterization using standard clinical protocols, and all coronary angiograms were reviewed by the experienced invasive cardiologists. According to result of CAG, patients were divided into non-obstructive CAS (NOCAS, $<50 \%$ luminal stenosis) group, intermediate CAS (ICAS, 50-69\% luminal stenosis) group, and severe CAS (SCAS, $70-100 \%$ luminal stenosis) group [16, 19, 20]. DM was diagnosed according to the American Diabetes Association criteria [21], defined as the fasting plasma glucose $\geq 7.0 \mathrm{mmol} / \mathrm{L}(126 \mathrm{mg} / \mathrm{dL})$, or 2 -h plasma glucose of the oral glucose tolerance test $\geq 11.1 \mathrm{mmol} / \mathrm{L}(200 \mathrm{mg} /$ $\mathrm{dL}$ ), or hemoglobin A1c (HbA1c) level $\geq 6.5 \%$, or patients with hypoglycemic drugs treatment. Diagnosed hypertension was defined with self-reported hypertension, and currently treatment of anti-hypertensive drugs. Undiagnosed hypertension was diagnosed with hospital recorded systolic blood pressure $\geq 140 \mathrm{mmHg}$ and/ or diastolic blood pressure $\geq 90 \mathrm{mmHg}$ for three or more consecutive times using standard mercury sphygmomanometer by trained physicians according to the guideline [22]. Body mass index (BMI) was calculated by dividing weight in kilograms by height in square meters. The diagnosis of other diseases, family history of CAD, and treatments were collected as previous study reported [23].

The endpoints were defined as major adverse cardiovascular events (MACE) covering cardiac death, non-fatal MI or ischemic stroke, unplanned coronary revascularization (including $\mathrm{PCI}$ and/or CABG), and unstable angina-related hospitalization. The detailed methods of follow-up visit have been reported as our previous study [23]. Each subject was actively followed up at 6-month intervals after the initial hospitalization, with outpatient clinic interviews or telephone contact by our well-trained cardiologists or nurses, who were blinded to the objectives of the present study.

\section{Laboratory tests}

Laboratory data were obtained from each patient with their venous blood samples taken after $12 \mathrm{~h}$ overnight at the initial entry in hospital, and all samples were stored in a $-80^{\circ} \mathrm{C}$ refrigerator until test. The lipid profiles were measured by automatic biochemistry analyzer (Hitachi 7150, Tokyo, Japan) followed the methods of our previous 


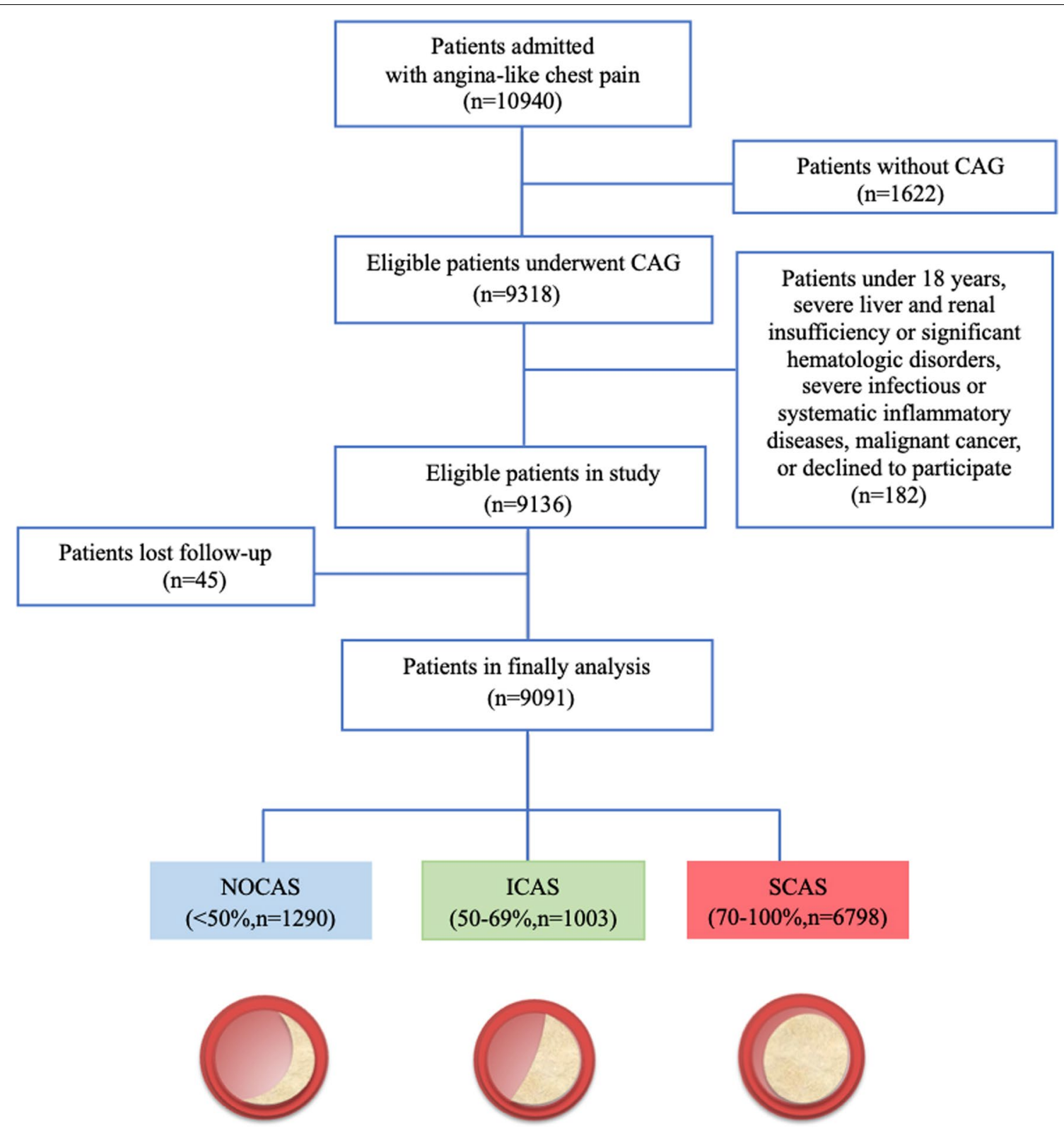

Fig. 1 Study flowchart. (CAG: coronary angiography; NOCAS: non-obstructive coronary artery stenosis; ICAS: intermediate coronary artery stenosis; SCAS: severe coronary artery stenosis)

study [23]. Detailly, the low-density lipoprotein cholesterol (LDL-C) concentrations were measured by selective solublilization method (low-density lipid cholesterol test kit; Kyowa Medex, Tokyo). High-density lipoprotein cholesterol (HDL-C) concentrations were analyzed using a homogeneous method (Determiner L HDL; Kyowa Medex, Tokyo). Total cholesterol, Triglyceride, Apolipoprotein A1 (ApoA1), and ApoB were measured by automatic biochemistry analyzer (Hitachi 7150, Tokyo, Japan) in an enzymatic assay. The fast glucose concentrations were measured by enzymatic hexokinase method. HbA1c was measured using Tosoh Automated Glycohemoglobin Analyser (HLC-723G8, Tokyo, Japan).

\section{Statistics}

Continuous data were showed as mean with standard deviation, or median with interquartile ranges. The Student t-test, Mann-Whitney U test, or the Kruskal-Wallis test was performed for subgroup comparisons as appropriate. Categorical data was presented with percentage 
(\%) and compared by Chi-square test, or Fisher's exact test. The risks of event in different subgroups were compared by Kaplan-Meier survival curves and log-rank test. The associations among DM, coronary stenosis, and clinical outcomes were analyzed by the unadjusted and adjusted Cox regression analyses [showed with hazard ratios (HR), and 95\% confidence intervals (CI)]. We performed statistical analyses with SPSS software version 23.0 (SPSS, Inc., Chicago, Illinois). A p value $<0.05$ was considered statistical significance.

\section{Results}

Baseline characteristics

The baseline characteristics of enrolled patients were shown in Table 1. Among the subjects, the average age was 57.2 years old and $70.7 \%(n=6431)$ were male. According to the result of CAG, patients were classified into three subgroups: NOCAS group $(n=1290)$, ICAS group $(n=1003)$, and SCAS group $(n=6798)$. Overall, $34.9 \%(n=3173)$ of them had DM. Patients with more severe coronary stenosis showed higher prevalence of DM (SCAS vs ICAS vs NOCAS: $38.1 \%$ vs $29.6 \%$ vs $22.3 \%, \mathrm{p}<0.001)$, and higher levels of fast glucose (SCAS vs ICAS vs NOCAS: $5.95 \pm 2.83 \mathrm{mmol} / \mathrm{L}$ vs $5.71 \pm 1.57 \mathrm{mmol} / \mathrm{L}$ vs $5.47 \pm 1.36 \mathrm{mmol} / \mathrm{L}, \mathrm{p}<0.001)$

Table 1 Baseline characteristics according to the severity of coronary artery stenosis

\begin{tabular}{|c|c|c|c|c|c|}
\hline Variables & Total & $\begin{array}{l}\text { NOCAS } \\
(<50 \%)\end{array}$ & $\begin{array}{l}\text { ICAS } \\
(50-69 \%)\end{array}$ & $\begin{array}{l}\text { SCAS } \\
(70-100 \%)\end{array}$ & $\begin{array}{l}\text { P value } \\
\text { for trend }\end{array}$ \\
\hline \multicolumn{6}{|l|}{ Baseline characteristics } \\
\hline Patients (n, \%) & 9091 & $1290(14.2 \%)$ & $1003(11.0 \%)$ & $6798(74.8 \%)$ & \\
\hline Age (years) & $57.22 \pm 10.37$ & $55.36 \pm 10.02$ & $57.43 \pm 9.85$ & $57.54 \pm 10.48$ & $<0.001$ \\
\hline Male $(n, \%)$ & $6431(70.7 \%)$ & $734(56.9 \%)$ & $644(64.2 \%)$ & $5053(74.3 \%)$ & $<0.001$ \\
\hline Hypertension (n, \%) & $5591(61.5 \%)$ & $680(52.7 \%)$ & $598(59.6 \%)$ & $4313(63.4 \%)$ & $<0.001$ \\
\hline Dyslipidemia (n, \%) & $6759(74.3 \%)$ & $860(66.7 \%)$ & $749(74.7 \%)$ & $5150(75.8 \%)$ & $<0.001$ \\
\hline Diabetes mellitus (n, \%) & $3173(34.9 \%)$ & $288(22.3 \%)$ & $297(29.6 \%)$ & $2588(38.1 \%)$ & $<0.001$ \\
\hline BMI $\left(\mathrm{kg} / \mathrm{m}^{2}\right)$ & $25.89 \pm 3.23$ & $25.68 \pm 3.41$ & $25.81 \pm 3.28$ & $25.94 \pm 3.19$ & 0.027 \\
\hline Current smoking (n, \%) & $2880(31.7 \%)$ & $306(23.7 \%)$ & $288(28.7 \%)$ & $2286(33.6 \%)$ & $<0.001$ \\
\hline Family history of CAD (n, \%) & 1207 (13.3\%) & $145(11.2 \%)$ & $125(12.5 \%)$ & $937(13.8 \%)$ & 0.034 \\
\hline \multicolumn{6}{|l|}{ Laboratory data } \\
\hline $\mathrm{TC}(\mathrm{mmol} / \mathrm{L})$ & $4.14 \pm 1.12$ & $4.22 \pm 0.95$ & $4.14 \pm 1.06$ & $4.13 \pm 1.16$ & 0.012 \\
\hline $\mathrm{TG}(\mathrm{mmol} / \mathrm{L})$ & $1.79 \pm 1.23$ & $1.77 \pm 1.27$ & $1.74 \pm 1.19$ & $1.80 \pm 1.23$ & 0.328 \\
\hline LDL-C (mmol/L) & $2.51 \pm 0.99$ & $2.54 \pm 0.83$ & $2.52 \pm 1.18$ & $2.51 \pm 0.92$ & 0.428 \\
\hline $\mathrm{HDL}-\mathrm{C}(\mathrm{mmol} / \mathrm{L})$ & $1.07 \pm 0.29$ & $1.12 \pm 0.32$ & $1.11 \pm 0.29$ & $1.05 \pm 0.29$ & $<0.001$ \\
\hline Apo A1 (g/L) & $1.34 \pm 0.30$ & $1.41 \pm 0.30$ & $1.38 \pm 0.29$ & $1.32 \pm 0.29$ & $<0.001$ \\
\hline Apo B (g/L) & $0.91 \pm 0.28$ & $0.92 \pm 0.27$ & $0.90 \pm 0.28$ & $0.92 \pm 0.29$ & 0.384 \\
\hline Glucose (mmol/L) & $5.85 \pm 2.56$ & $5.47 \pm 1.36$ & $5.71 \pm 1.57$ & $5.95 \pm 2.83$ & $<0.001$ \\
\hline $\mathrm{HbA1c}(\%)$ & $6.29 \pm 1.09$ & $6.00 \pm 0.86$ & $6.16 \pm 0.92$ & $6.37 \pm 1.15$ & $<0.001$ \\
\hline Creatinine (mmol/L) & $77.33 \pm 17.46$ & $73.23 \pm 15.14$ & $75.63 \pm 19.53$ & $78.36 \pm 17.4$ & $<0.001$ \\
\hline \multicolumn{6}{|l|}{ Treatment in hospital } \\
\hline Aspirin (n, \%) & 8595 (94.5\%) & $1166(90.4 \%)$ & $959(95.6 \%)$ & $6470(95.2 \%)$ & $<0.001$ \\
\hline$\beta$-Blockers (n, \%) & $6846(75.3 \%)$ & 795 (61.6\%) & $700(69.8 \%)$ & $5351(78.7 \%)$ & $<0.001$ \\
\hline CCBs $(n, \%)$ & $3356(36.9 \%)$ & 469 (36.4\%) & 399 (39.8\%) & $2488(36.6 \%)$ & 0.135 \\
\hline ACE inhibitors (n, \%) & 2045 (22.5\%) & $228(17.7 \%)$ & $174(17.3 \%)$ & $1643(24.2 \%)$ & $<0.001$ \\
\hline $\operatorname{ARB}(n, \%)$ & $2150(23.6 \%)$ & $265(20.5 \%)$ & $243(24.2 \%)$ & $1642(24.2 \%)$ & 0.018 \\
\hline Lipid-lowering medication (n, \%) & $8159(89.7 \%)$ & $1056(81.9 \%)$ & $898(89.5 \%)$ & $6205(91.3 \%)$ & $<0.001$ \\
\hline Anti-diabetes drugs (n, \%) & $3173(34.9 \%)$ & $288(22.3 \%)$ & 297 (29.6\%) & $2588(38.1 \%)$ & $<0.001$ \\
\hline MACE $(n, \%)$ & $1017(11.1 \%)$ & $90(7.0 \%)$ & $94(9.4 \%)$ & $833(12.3 \%)$ & $<0.001$ \\
\hline
\end{tabular}

NOCAS non-obstructive coronary artery stenosis, ICAS intermediate coronary artery stenosis, SCAS severe coronary artery stenosis, $B M I$ body mass index, LVEF left ventricular ejection fraction, $C A D$ coronary artery disease, $T C$ total cholesterol, $T G$ triglyceride, $L D L-C$ low-density lipoprotein cholesterol, $H D L-C$ high-density lipoprotein cholesterol, $A p o$ apolipoprotein, $H b A 1 c$ hemoglobin A1c, CCBs calcium channel blockers, $A C E$ angiotensin converting enzyme, $A R B$ angiotensin receptor blocker, MACE major adverse cardiovascular event 
and HbA1c (SCAS vs ICAS vs NOCAS: $6.37 \pm 1.15 \%$ vs $6.16 \pm 0.92 \%$ vs $6.00 \pm 0.86 \%, \mathrm{p}<0.001)$. Besides, patients were more likely to have hypertension, dyslipidemia, current smoking, and family history of CAD with the increase in the degree of CAS (all $\mathrm{p}<0.05$ ).

During a median follow-up of 40 months, there were 1,017 (11.1\%) MACEs occurred, including 104 cardiac death, 75 non-fatal MI, 170 non-fatal stroke, 289 coronary revascularization, and 379 angina-related hospitalization. Notably, the incidence of MACEs increased in patients with SCAS when compared with those in ICAS and NOCAS groups $(12.3 \%$ vs $9.4 \%$ vs $7.0 \%, \mathrm{p}<0.001)$.

\section{Diabetes, coronary stenosis, and outcomes}

As shown in Table 2, patients with MACEs had higher incidence of $\mathrm{DM}$ and hypertension $(\mathrm{p}<0.001$, respectively). They also showed increased levels of HbA1c $(6.47 \pm 1.20 \%$ vs $6.27 \pm 1.09 \%, \mathrm{p}<0.001)$. Moreover, there was a higher percentage of SCAS in patients with MACEs compared to those without $(81.9 \%$ vs $73.9 \%, \mathrm{p}<0.001)$.

Table 2 Baseline characteristics in patients with or without cardiovascular events

\begin{tabular}{|c|c|c|c|c|}
\hline Variables & Total & MACE & Non-MACE & $P$ value \\
\hline \multicolumn{5}{|l|}{ Baseline characteristics } \\
\hline Patients (n, \%) & 9091 & $1017(11.1 \%)$ & $8074(88.9 \%)$ & \\
\hline Age (years) & $57.22 \pm 10.37$ & $59.81 \pm 9.98$ & $56.89 \pm 10.38$ & $<0.001$ \\
\hline Male (n, \%) & $6431(70.7 \%)$ & $687(67.6 \%)$ & $5744(71.1 \%)$ & 0.018 \\
\hline Hypertension (n, \%) & $5591(61.5 \%)$ & $677(66.6 \%)$ & $4914(60.9 \%)$ & $<0.001$ \\
\hline Dyslipidemia (n, \%) & $6759(74.3 \%)$ & $751(73.8 \%)$ & $6008(74.4 \%)$ & 0.696 \\
\hline Diabetes mellitus (n, \%) & 3173 (34.9\%) & $425(41.8 \%)$ & $2748(34.0 \%)$ & $<0.001$ \\
\hline $\mathrm{BMI}\left(\mathrm{kg} / \mathrm{m}^{2}\right)$ & $25.89 \pm 3.23$ & $25.74 \pm 3.23$ & $25.90 \pm 3.23$ & 0.121 \\
\hline Current smoking $(n, \%)$ & $2880(31.7 \%)$ & $280(27.5 \%)$ & $2600(32.2 \%)$ & 0.003 \\
\hline Family history of CAD $(n, \%)$ & $1207(13.3 \%)$ & $130(12.8 \%)$ & $1077(13.3 \%)$ & 0.622 \\
\hline \multicolumn{5}{|l|}{ Laboratory data } \\
\hline $\mathrm{TC}(\mathrm{mmol} / \mathrm{L})$ & $4.14 \pm 1.12$ & $4.15 \pm 1.12$ & $4.14 \pm 1.12$ & 0.805 \\
\hline $\mathrm{TG}(\mathrm{mmol} / \mathrm{L})$ & $1.79 \pm 1.23$ & $1.81 \pm 1.47$ & $1.79 \pm 1.20$ & 0.580 \\
\hline LDL-C (mmol/L) & $2.51 \pm 0.99$ & $2.49 \pm 0.92$ & $2.51 \pm 1.00$ & 0.532 \\
\hline $\mathrm{HDL}-\mathrm{C}(\mathrm{mmol} / \mathrm{L})$ & $1.07 \pm 0.29$ & $1.07 \pm 0.29$ & $1.07 \pm 0.29$ & 0.569 \\
\hline Apo A1 (g/L) & $1.34 \pm 0.30$ & $1.36 \pm 0.30$ & $1.34 \pm 0.30$ & 0.086 \\
\hline Apo B (g/L) & $0.91 \pm 0.28$ & $0.93 \pm 0.30$ & $0.91 \pm 0.29$ & 0.211 \\
\hline Glucose (mmol/L) & $5.85 \pm 2.56$ & $5.87 \pm 1.80$ & $5.83 \pm 1.75$ & 0.551 \\
\hline $\mathrm{HbA1c}(\%)$ & $6.29 \pm 1.09$ & $6.47 \pm 1.20$ & $6.27 \pm 1.09$ & $<0.001$ \\
\hline Creatinine (mmol/L) & $77.33 \pm 17.46$ & $77.93 \pm 17.29$ & $77.25 \pm 17.48$ & 0.246 \\
\hline \multicolumn{5}{|l|}{ Treatment in hospital } \\
\hline Aspirin (n, \%) & 8595 (94.5\%) & $984(96.8 \%)$ & $7611(94.3 \%)$ & 0.001 \\
\hline$\beta$-Blockers (n, \%) & $6846(75.3 \%)$ & $802(78.9 \%)$ & $6044(74.9 \%)$ & 0.005 \\
\hline $\operatorname{CCBs}(n, \%)$ & $3356(36.9 \%)$ & $403(39.6 \%)$ & $2953(36.6 \%)$ & 0.057 \\
\hline ACE inhibitors (n, \%) & $2045(22.5 \%)$ & $273(26.8 \%)$ & $1772(21.9 \%)$ & $<0.001$ \\
\hline $\operatorname{ARB}(n, \%)$ & $2150(23.6 \%)$ & $291(28.6 \%)$ & $1859(23.0 \%)$ & $<0.001$ \\
\hline Lipid-lowering medication ( $n, \%)$ & $8159(89.7 \%)$ & $958(94.2 \%)$ & 7201 (89.2\%) & $<0.001$ \\
\hline Anti-diabetes drugs (n, \%) & $3173(34.9 \%)$ & $425(41.8 \%)$ & $2748(34.0 \%)$ & $<0.001$ \\
\hline Coronary revascularization ( $\mathrm{n}, \%)$ & 4493 (49.4\%) & $500(49.2 \%)$ & $3993(49.6 \%)$ & 0.861 \\
\hline \multicolumn{5}{|l|}{ Severity of coronary disease } \\
\hline $\operatorname{NOCAS}(n, \%)$ & $1290(14.2 \%)$ & $90(8.8 \%)$ & $1200(14.9 \%)$ & $<0.001$ \\
\hline ICAS $(n, \%)$ & $1003(11.0 \%)$ & $94(9.2 \%)$ & 909 (11.3\%) & 0.056 \\
\hline $\operatorname{SCAS}(n, \%)$ & $6798(74.8 \%)$ & 833 (81.9\%) & 5965 (73.9\%) & $<0.001$ \\
\hline
\end{tabular}

MACE major adverse cardiovascular event, $B M I$ body mass index, LVEF left ventricular ejection fraction, CAD coronary artery disease, TC total cholesterol, TG triglyceride, $L D L$-C low-density lipoprotein cholesterol, $H D L-C$ high-density lipoprotein cholesterol, Apo apolipoprotein, $H b A 1 c$ hemoglobin $A 1 C, C C B s$ calcium channel blockers, ACE angiotensin converting enzyme, ARB angiotensin receptor blocker, NOCAS non-obstructive coronary artery stenosis, ICAS intermediate coronary artery stenosis, SCAS severe coronary artery stenosis

Values are expressed as the mean \pm SD, or $\mathrm{n}(\%)$. Bold $\mathrm{P}$ means statistically significant 
There was no significantly difference in coronary revascularization between patients with and without MACEs ( $p>0.05$ ). According to the status of glucose metabolism, the patients were further categorized into six subgroups as NOCAS with DM and non-DM group, ICAS with DM and non-DM group, and SCAS with DM and nonDM group. The incidence of MACEs in different subgroups were presented in Fig. 2. In patients with ICAS or SCAS, the incidence of MACEs was higher when patients

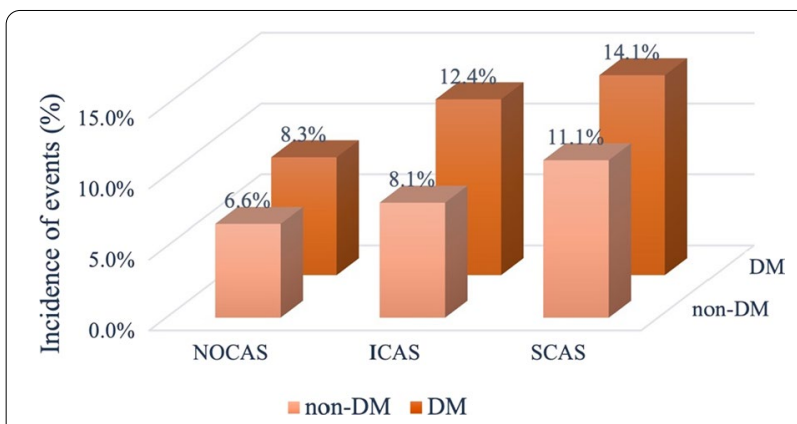

Fig. 2 The incidence of cardiovascular events in different subgroups. (NOCAS: non-obstructive coronary artery stenosis; ICAS: intermediate coronary artery stenosis; SCAS: severe coronary artery stenosis; DM: diabetes mellitus) coexisted with DM (ICAS: $12.4 \%$ vs $8.1 \%$; SCAS: $14.1 \%$ vs 11.1\%; $\mathrm{p}<0.05$, respectively). Patients in SCAS with DM group showed the highest incidence of MACEs (14.1\%). Interestingly, among the patients with DM, the incidence of MACEs in patients with NOCAS was similar to that in ICAS without DM (8.3\% vs $8.1 \%)$, and the incidence of MACEs in patients with ICAS was similar to that in SCAS without DM (12.4\% vs $11.1 \%)$.

Besides, as shown in Fig. 3, the Kaplan-Meier analysis curves presented the highest risk of MACEs in patients with SCAS and DM compared with other subgroups (log rank test, $\mathrm{p}<0.001)$. Furthermore, we assessed the prognostic utility in patients presented different extent of coronary stenosis with or without DM by Cox regression analysis in Fig. 4. Obviously, in unadjusted model, patients with ICAS and DM, SCAS and non-DM, SCAS and DM showed increased risk of MACEs (Fig. 4A: HR: 2.005; 95\% CI 1.341-2.999, $\mathrm{p}=0.001$; HR: 1.868 ; 95\% CI 1.444-2.418, p<0.001; HR: 2.357; 95\% CI 1.813-3.063, $\mathrm{p}<0.001$; respectively) compared to those in NOCAS and non-DM group (as reference). Particularly, there was a comparable risk of MACEs in patients with ICAS plus DM and patients with SCAS alone. The results remained after adjusted for age, gender, hypertension, dyslipidemia, BMI, current smoking, family history of CAD,

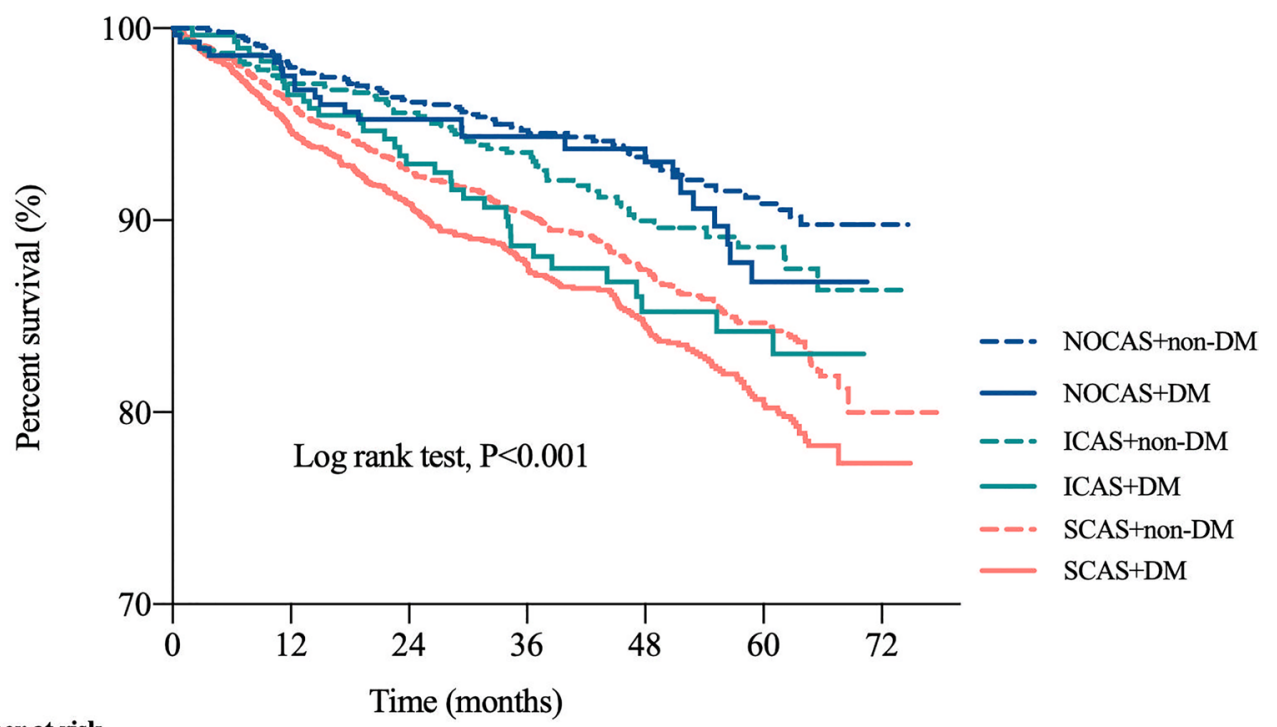

Number at risk

$\begin{array}{llllllll}\text { NOCAS+non-DM } & 1002 & 958 & 779 & 602 & 429 & 279 & 2 \\ \text { NOCAS+DM } & 288 & 272 & 217 & 173 & 134 & 86 & 1 \\ \text { ICAS+non-DM } & 704 & 667 & 534 & 407 & 272 & 160 & 1 \\ \text { ICAS+DM } & 299 & 279 & 214 & 163 & 111 & 72 & 1 \\ \text { SCAS+non-DM } & 4212 & 3902 & 2946 & 2194 & 1415 & 810 & 8 \\ \text { SCAS+DM } & 2586 & 2388 & 1824 & 1335 & 898 & 542 & 5\end{array}$

Fig. 3 Kaplan-Meier curves in different subgroups. Figure 3 showed the Kaplan-Meier curves in patients with or without diabetes according to the severity of coronary artery stenosis. (NOCAS: non-obstructive coronary artery stenosis; ICAS: intermediate coronary artery stenosis; SCAS: severe coronary artery stenosis; DM: diabetes mellitus) 
A

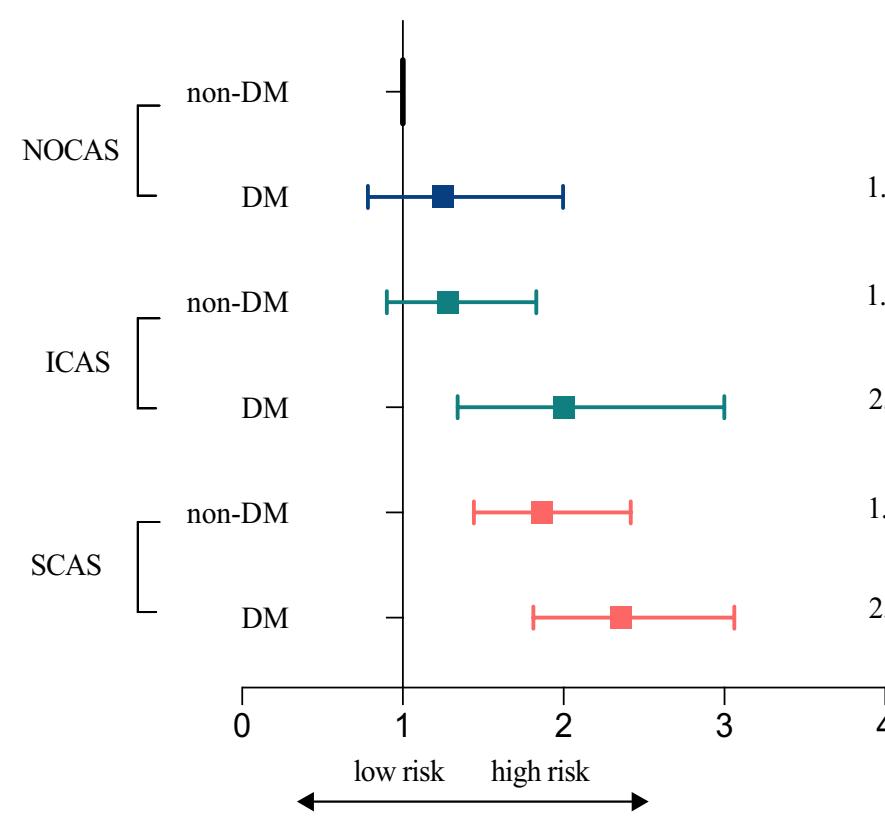

B

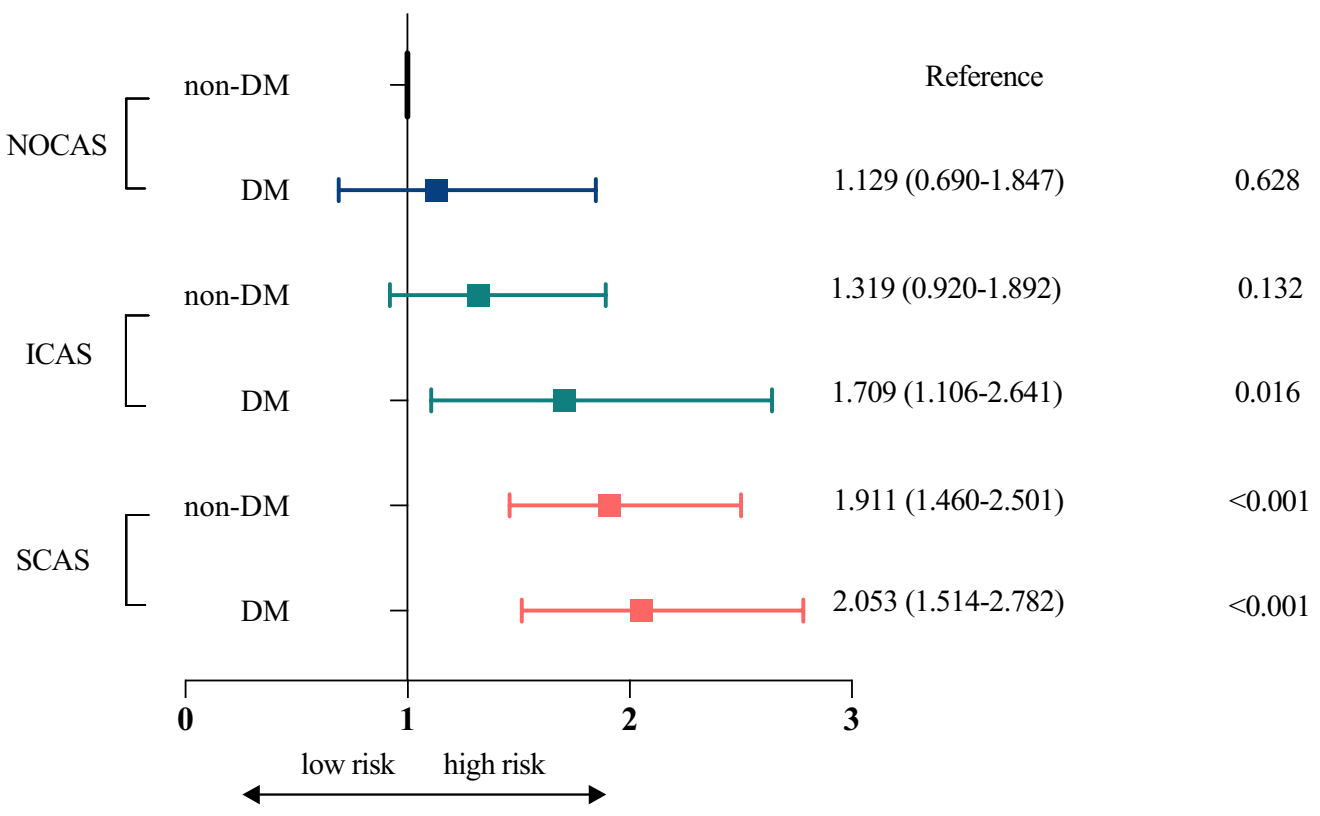

Fig. 4 Cox regression analyses of cardiovascular events in different subgroups. A showed the unadjusted model. B showed the adjusted model after adjustment for age, gender, hypertension, dyslipidemia, body mass index, current smoking, family history of coronary artery disease, glucose, and hemoglobin A1c. (NOCAS: non-obstructive coronary artery stenosis; ICAS: intermediate coronary artery stenosis; SCAS: severe coronary artery stenosis; DM: diabetes mellitus; HRs: hazard ratios; Cls: confidential intervals)

glucose, and HbA1c (Fig. 4B: adjusted HR: 1.709; 95\% CI $1.106-2.641, \mathrm{p}=0.016$; adjusted HR: $1.911 ; 95 \%$ CI 1.460-2.501, $\mathrm{p}<0.001$; adjusted HR: 2.053; 95\% CI 1.514$2.782, \mathrm{p}<0.001)$.

\section{Discussion}

In this perspective, observational study on a large Chinese cohort with long-term follow-up, we examined the prognostic association of DM with outcomes in patients 
with different degree of CAS assessed by CAG. Our data indicated that diabetic patients with ICAS and SCAS were both associated with significantly increased risks of MACEs compared to ones with a mild coronary stenosis, even after adjusting for traditional cardiovascular risk factors. These findings suggested that more precise risk assessment should be performed in diabetic patients with different coronary stenosis.

Previously, a number of observational and prospective studies have reported the relation of coronary stenosis severity to the development of cardiovascular events [2426]. On the one hand, evidence has revealed that acute coronary events commonly arise from severely stenotic lesions, since patients occurred acute coronary syndrome were found to have severe coronary stenosis [24, 25]. For example, Frøbert et al. have revealed that above $90 \%$ of patients with acute MI presented with much than $50 \%$ stenosis of coronary arteries, and above $60 \%$ of them presented with much than $70 \%$ stenosis of coronary arteries [25]. These data suggested that severe lumen stenosis appeared to be an important prerequisite for acute coronary events. On the other hand, patients with severe coronary stenosis were more likely to develop increased cardiovascular events. Data obtained from series of prospective studies supported this notion [19, 26, 27]. For instance, a recent study indicated that physiological stenosis severity assessed by fractional flow reserve was closely related to the plaque vulnerability assessed by CTA, and was significantly associated with the risk of clinical events [27]. Another angiographic study from Zaman et al. also reported that severe coronary stenosis was a valuable predictor for acute coronary events in the subsequent follow-up duration [26]. Results from the international multicenter prospective study, CONFIRM (Coronary CT Angiography Evaluation for Clinical Outcomes: An International Multicenter Registry), were similar to prior studies, which have demonstrated that the extent and severity of CAD was an indicator for poor prognosis [28]. Moreover, they reported that both non-obstructive and obstructive CAD were associated with increased all-cause mortality, whether using a definition of non-obstructive stenosis range from 1 to $49 \%$ or $1 \%$ to $69 \%$ [20]. Based on above studies, we have carefully examined the relation of coronary stenosis to clinical outcomes and tested this interesting phenomenon in Chinese population. In line with the previous studies, our data indicated that patients with severe stenosis $(70-100 \%)$ of coronary arteries assessed by CAG had the highest clinical events than ones with mild-tointermediate stenosis (SCAS vs ICAS vs NOCAS: $12.3 \%$ vs $9.4 \%$ vs $7.0 \%$ ). Furthermore, we found that patients with ICAS plus DM had a comparable risk of MACEs to patients with SCAS alone (unadjusted HR: 2.005 vs 1.868; adjusted HR: 1.709 vs 1.911).

In fact, it is well-recognized that diabetes is an independent risk factor for the development of CAD, and there was robust evidence demonstrating the high prevalence of adverse cardiovascular risk in diabetic individuals $[2-6,8]$. The CONFIRM study indicated that diabetic patients had a higher prevalence and severity of CAD compared with matched patients without DM [8]. Moreover, coronary lesions in patients with DM usually present greater atherosclerotic plaque burden, and are even more complicated characterized by diffuse, calcified, multivessel diseases, and smaller coronary artery lumen diameter than ones without DM $[9-11,29]$. A recent study with a small sample of diabetic patients explored the impact of diabetes duration on the extent and severity of coronary stenosis measured by coronary CTA, and they found that longer DM duration was associated with a higher prevalence and severity of $\mathrm{CAD}$ as well as risk of MACE, and greater coronary disease had increased risk of MACE independent of co-existing CAD risk factors [7]. However, till now, there is limited information concerning the prognostic association of DM and outcomes in patients with different degree of coronary stenosis. That is the reason why we performed the present study. In our observation, we determined the prognostic performance of coronary stenosis in patients with or without DM for the prediction of MACE. Interestingly, data showed that patients with ICAS plus DM had a comparable risk of MACE to ones with SCAS without DM. This data provided complementary information regarding the association of diabetes, coronary stenosis with outcomes, which expanded previous evidence of the impact of diabetes on clinical outcomes in patients with coronary atherosclerosis.

Given the clinical burden that diabetes exerted on cardiovascular risk complications, the joint evaluations of diabetes and coronary stenosis are of clinical significance for management of these patients. Hence, recent guidelines and expert consensus have been characterized by further emphasizing the assessment risk factors combined with obvious cardiovascular pathological lesions in patients with diabetes $[6,17]$. The potential mechanism of diabetes as a risk factor of cardiovascular diseases might because of hyperglycemia influences the pathology of coronary microvascular, inflammation and sympathetic nervous system activity, vasospastic and structural remodeling of circulation, resulting in an increased cardiovascular risk [17, 30]. Although our study did not provide the detailed mechanism exploration, the present study might support the notion that diabetes could impose a bad impact on the adverse 
outcome in patients with CAD, even in those with intermediate coronary stenosis.

Our study had several limitations. Firstly, as the nature of an observational studies, our study was subject to selection and misclassification bias. Secondly, the coronary stenosis percent was defined by CAG, the evaluation of stenosis was measured by semiquantitative visual analysis rather than by other volumetric quantification and functional tests for the stenotic arteries. Moreover, although the patients enrolled in this study received the optimal medical therapy for secondary prevention when they were discharged from hospital, the detailed data covering medications and hypoglycemic agents were not available during the follow-up. Finally, our study was a single center study, and the sample size in subgroup was relatively small. Therefore, future studies are needed to confirm our findings.

\section{Conclusions}

The present study provided an insight regarding the association of DM with cardiovascular outcomes in patients with different degree of coronary stenosis in a large Chinese cohort. Our results indicated that patients with DM and intermediate stenotic coronary lesion presented worse outcomes and were comparable to patients with severe coronary stenosis alone, suggesting that more intensive managements might be needed in such patients.

\section{Abbreviations \\ CAD: Coronary artery disease; DM: Diabetes mellitus; HbA1c: Hemoglobin A1c; CAG: Coronary angiography; MACE: Major adverse cardiovascular events; HR: Hazard ratio; Cl: Confidence interval.}

\section{Acknowledgements}

The authors thank all the staff and participants of this study for their important contributions.

\begin{abstract}
Authors' contributions
H-WZ analyzed data and wrote the manuscript. H-WZ, J-LJ, Y-XC, J-JL contributed to data interpretation, data collection, and the editing of the manuscript. H-WZ, J-JL were responsible for study design and collection of study data. Y-LG, N-QW, C-GZ, R-XX, QD, J-JL contributed to recruitment of patients and data collection, J-JL designed the study and contributed to critically revising the manuscript. All authors have read and approved the final manuscript.
\end{abstract}

\section{Funding}

This work was partially supported by the Capital Health Development Fund (201614035), CAMS Major Collaborative Innovation Project (2016-I2M-1-011), and Chinese Cardiovascular Association-V.G fund (2017-CCA-VG-017).

\section{Availability of data and materials}

The datasets used and/or analyzed during the current study are available from the corresponding author on reasonable request.

\section{Declarations}

\section{Ethics approval and consent to participate}

The study complied with the Declaration of Helsinki and was approved by the hospital ethical review board (FuWai Hospital and National Center for Cardiovascular Diseases, Beijing, China). The informed written consent was obtained from all patients.

\section{Consent for publication}

Not applicable.

\section{Competing interests}

The authors declare that they have no competing interests.

Received: 17 June 2021 Accepted: 15 October 2021

Published online: 23 October 2021

\section{References}

1. Cosentino F, Grant PJ, Aboyans V, Bailey CJ, Ceriello A, Delgado V, Federici M, Filippatos G, Grobbee DE, Hansen TB, et al. 2019 ESC Guidelines on diabetes, pre-diabetes, and cardiovascular diseases developed in collaboration with the EASD. Eur Heart J. 2020;41(2):255-323.

2. Wright AK, Kontopantelis E, Emsley R, Buchan I, Mamas MA, Sattar N, Ashcroft DM, Rutter MK. Cardiovascular risk and risk factor management in type 2 diabetes mellitus. Circulation. 2019;139(24):2742-53.

3. Einarson TR, Acs A, Ludwig C, Panton UH. Prevalence of cardiovascular disease in type 2 diabetes: a systematic literature review of scientific evidence from across the world in 2007-2017. Cardiovasc Diabetol. 2018;17(1):83.

4. Tancredi M, Rosengren A, Svensson AM, Kosiborod M, Pivodic A, Gudbjornsdottir S, Wedel H, Clements M, Dahlqvist S, Lind M. Excess mortality among persons with type 2 diabetes. N Engl J Med. 2015;373(18):1720-32.

5. Whiteley L, Padmanabhan S, Hole D, Isles C. Should diabetes be considered a coronary heart disease risk equivalent?: Results from 25 years of follow-up in the Renfrew and Paisley survey. Diabetes Care. 2005;28(7):1588-93.

6. Das SR, Everett BM, Birtcher KK, Brown JM, Januzzi JL Jr, Kalyani RR, Kosiborod M, Magwire M, Morris PB, Neumiller JJ, et al. 2020 expert consensus decision pathway on novel therapies for cardiovascular risk reduction in patients with type 2 diabetes: a report of the American College of Cardiology Solution Set Oversight Committee. J Am Coll Cardiol. 2020;76(9):1117-45.

7. Kim JJ, Hwang BH, Choi IJ, Choo EH, Lim S, Kim JK, Koh YS, Kim DB, Jang SW, Cho EJ, et al. Impact of diabetes duration on the extent and severity of coronary atheroma burden and long-term clinical outcome in asymptomatic type 2 diabetic patients: evaluation by coronary CT angiography. Eur Heart J Cardiovasc Imaging. 2015;16(10):1065-73.

8. Rana JS, Dunning A, Achenbach S, Al-Mallah M, Budoff MJ, Cademartiri F, Callister TQ, Chang HJ, Cheng VY, Chinnaiyan K, et al. Differences in prevalence, extent, severity, and prognosis of coronary artery disease among patients with and without diabetes undergoing coronary computed tomography angiography: results from 10,110 individuals from the CONFIRM (COronary CT Angiography EvaluatioN For Clinical Outcomes): an InteRnational Multicenter Registry. Diabetes Care. 2012;35(8):1787-94.

9. Beckman JA, Creager MA, Libby P. Diabetes and atherosclerosis: epidemiology, pathophysiology, and management. JAMA. 2002;287(19):2570-81.

10. Nicholls SJ, Tuzcu EM, Kalidindi S, Wolski K, Moon KW, Sipahi I, Schoenhagen $\mathrm{P}$, Nissen SE. Effect of diabetes on progression of coronary atherosclerosis and arterial remodeling: a pooled analysis of 5 intravascular ultrasound trials. J Am Coll Cardiol. 2008;52(4):255-62.

11. Paneni F, Beckman JA, Creager MA, Cosentino F. Diabetes and vascular disease: pathophysiology, clinical consequences, and medical therapy: part I. Eur Heart J. 2013;34(31):2436-43.

12. Reeh J, Therming CB, Heitmann M, Hojberg S, Sorum C, Bech J, Husum D, Dominguez H, Sehestedt T, Hermann T, et al. Prediction of obstructive 
coronary artery disease and prognosis in patients with suspected stable angina. Eur Heart J. 2019;40(18):1426-35.

13. Knuuti J, Wijns W, Saraste A, Capodanno D, Barbato E, Funck-Brentano C, Prescott E, Storey RF, Deaton C, Cuisset T, et al. 2019 ESC Guidelines for the diagnosis and management of chronic coronary syndromes. Eur Heart J. 2020;41(3):407-77.

14. Sharaf B, Wood T, Shaw L, Johnson BD, Kelsey S, Anderson RD, Pepine CJ, Bairey Merz CN. Adverse outcomes among women presenting with signs and symptoms of ischemia and no obstructive coronary artery disease: findings from the National Heart, Lung, and Blood Institute-sponsored Women's Ischemia Syndrome Evaluation (WISE) angiographic core laboratory. Am Heart J. 2013;166(1):134-41.

15. Jespersen L, Abildstrom SZ, Hvelplund A, Prescott E. Persistent angina: highly prevalent and associated with long-term anxiety, depression, low physical functioning, and quality of life in stable angina pectoris. Clin Res Cardiol. 2013;102(8):571-81.

16. Jespersen L, Hvelplund A, Abildstrom SZ, Pedersen F, Galatius S, Madsen JK, Jorgensen E, Kelbaek H, Prescott E. Stable angina pectoris with no obstructive coronary artery disease is associated with increased risks of major adverse cardiovascular events. Eur Heart J. 2012;33(6):734-44.

17. Kunadian V, Chieffo A, Camici PG, Berry C, Escaned J, Maas A, Prescott E, Karam N, Appelman Y, Fraccaro C, et al. An EAPCl expert consensus document on ischaemia with non-obstructive coronary arteries in collaboration with European Society of Cardiology Working Group on Coronary Pathophysiology \& Microcirculation Endorsed by Coronary Vasomotor Disorders International Study Group. Eur Heart J. 2020;41(37):3504-20.

18. Scanlon PJ, Faxon DP, Audet AM, Carabello B, Dehmer GJ, Eagle KA, Legako RD, Leon DF, Murray JA, Nissen SE, et al. ACC/AHA guidelines for coronary angiography: executive summary and recommendations. A report of the American College of Cardiology/American Heart Association Task Force on Practice Guidelines (Committee on Coronary Angiography) developed in collaboration with the Society for Cardiac Angiography and Interventions. Circulation. 1999;99(17):2345-57.

19. Tian J, Dauerman H, Toma C, Samady H, Itoh T, Kuramitsu S, Domei T, Jia $H$, Vergallo R, Soeda T, et al. Prevalence and characteristics of TCFA and degree of coronary artery stenosis: an OCT, IVUS, and angiographic study. J Am Coll Cardiol. 2014;64(7):672-80.

20. Nakazato R, Arsanjani R, Achenbach S, Gransar H, Cheng VY, Dunning A, Lin FY, Al-Mallah M, Budoff MJ, Callister TQ, et al. Age-related risk of major adverse cardiac event risk and coronary artery disease extent and severity by coronary CT angiography: results from 15187 patients from the International Multisite CONFIRM Study. Eur Heart J Cardiovasc Imaging. 2014;15(5):586-94.

21. American Diabetes A. 2. Classification and diagnosis of diabetes: standards of medical care in diabetes-2019. Diabetes Care. 2019;42(Suppl 1):S13-28.

22. Williams B, Mancia G, Spiering W, Agabiti Rosei E, Azizi M, Burnier M, Clement DL, Coca A, de Simone G, Dominiczak A, et al. 2018 ESC/ESH guidelines for the management of arterial hypertension. Eur Heart J. 2018;39(33):3021-104.

23. Jin JL, Cao YX, Zhang HW, Sun D, Hua Q, Li YF, Guo YL, Wu NQ, Zhu CG, Gao $Y$, et al. Lipoprotein(a) and cardiovascular outcomes in patients with coronary artery disease and prediabetes or diabetes. Diabetes Care. 2019;42(7):1312-8.

24. Manoharan G, Ntalianis A, Muller O, Hamilos M, Sarno G, Melikian N, Vanderheyden M, Heyndrickx GR, Wyffels E, Wijns W, et al. Severity of coronary arterial stenoses responsible for acute coronary syndromes. Am J Cardiol. 2009;103(9):1183-8.

25. Ambrose JA, Tannenbaum MA, Alexopoulos D, Hjemdahl-Monsen CE, Leavy J, Weiss M, Borrico S, Gorlin R, Fuster V. Angiographic progression of coronary artery disease and the development of myocardial infarction. J Am Coll Cardiol. 1988;12(1):56-62.

26. Zaman T, Agarwal S, Anabtawi AG, Patel NS, Ellis SG, Tuzcu EM, Kapadia SR. Angiographic lesion severity and subsequent myocardial infarction. Am J Cardiol. 2012;110(2):167-72.

27. Lee JM, Choi KH, Koo BK, Park J, Kim J, Hwang D, Rhee TM, Kim HY, Jung HW, Kim KJ, et al. Prognostic implications of plaque characteristics and stenosis severity in patients with coronary artery disease. J Am Coll Cardiol. 2019;73(19):2413-24.

28. Min JK, Dunning A, Lin FY, Achenbach S, Al-Mallah M, Budoff MJ, Cademartiri F, Callister TQ, Chang HJ, Cheng V, et al. Age- and sex-related differences in all-cause mortality risk based on coronary computed tomography angiography findings results from the International Multicenter CONFIRM (Coronary CT Angiography Evaluation for Clinical Outcomes: An International Multicenter Registry) of 23,854 patients without known coronary artery disease. J Am Coll Cardiol. 2011;58(8):849-60.

29. Katakami N. Mechanism of development of atherosclerosis and cardiovascular disease in diabetes mellitus. J Atheroscler Thromb. 2018:25(1):27-39.

30. Paolisso P, Foa A, Bergamaschi L, Angeli F, Fabrizio M, Donati F, Toniolo S, Chiti C, Rinaldi A, Stefanizzi A, et al. Impact of admission hyperglycemia on short and long-term prognosis in acute myocardial infarction: MINOCA versus MIOCA. Cardiovasc Diabetol. 2021;20(1):192.

\section{Publisher's Note}

Springer Nature remains neutral with regard to jurisdictional claims in published maps and institutional affiliations.
Ready to submit your research? Choose BMC and benefit from:

- fast, convenient online submission

- thorough peer review by experienced researchers in your field

- rapid publication on acceptance

- support for research data, including large and complex data types

- gold Open Access which fosters wider collaboration and increased citations

- maximum visibility for your research: over $100 \mathrm{M}$ website views per year

At BMC, research is always in progress.

Learn more biomedcentral.com/submissions 